\title{
Aggravation of viral hepatitis by platelet-derived serotonin
}

\author{
Philipp A Lang ${ }^{1,2,10}$, Claudio Contaldo ${ }^{3,10}$, Panco Georgiev ${ }^{4,10}$, Ashraf Mohammad El-Badry ${ }^{4}$, Mike Recher ${ }^{1}$, \\ Michael Kurrer ${ }^{5}$, Luisa Cervantes-Barragan ${ }^{6}$, Burkhard Ludewig ${ }^{6}$, Thomas Calzascia ${ }^{2}$, Beatrice Bolinger ${ }^{6}$, \\ Doron Merkler ${ }^{1,7}$, Bernhard Odermatt ${ }^{5}$, Michael Bader ${ }^{8}$, Rolf Graf ${ }^{4}$, Pierre-Alain Clavien ${ }^{4}$, \\ Ahmed N Hegazy ${ }^{1,9}$, Max Löhning ${ }^{1,9}$, Nicola L Harris ${ }^{1}$, Pamela S Ohashi ${ }^{2}$, Hans Hengartner ${ }^{1}$, \\ Rolf M Zinkernagel ${ }^{1,11}$ \& Karl S Lang ${ }^{1,2,11}$
}

More than $\mathbf{5 0 0}$ million people worldwide are persistently infected with hepatitis B virus or hepatitis $C$ virus ${ }^{1}$. Although both viruses are poorly cytopathic, persistence of either virus carries a risk of chronic liver inflammation, potentially resulting in liver steatosis, liver cirrhosis, end-stage liver failure or hepatocellular carcinoma. Virus-specific T cells are a major determinant of the outcome of hepatitis, as they contribute to the early control of chronic hepatitis viruses, but they also mediate immunopathology during persistent virus infection ${ }^{1-4}$. We have analyzed the role of platelet-derived vasoactive serotonin during virus-induced $\mathrm{CD} 8^{+} \mathrm{T}$ cell-dependent immunopathological hepatitis in mice infected with the noncytopathic lymphocytic choriomeningitis virus. After virus infection, platelets were recruited to the liver, and their activation correlated with severely reduced sinusoidal microcirculation, delayed virus elimination and increased immunopathological liver cell damage. Lack of platelet-derived serotonin in serotonin-deficient mice normalized hepatic microcirculatory dysfunction, accelerated virus clearance in the liver and reduced $\mathrm{CD}^{+} \mathrm{T}$ cell-dependent liver cell damage. In keeping with these observations, serotonin treatment of infected mice delayed entry of activated CD8 ${ }^{+} \mathrm{T}$ cells into the liver, delayed virus control and aggravated immunopathological hepatitis. Thus, vasoactive serotonin supports virus persistence in the liver and aggravates virus-induced immunopathology.

Infection of mice with the noncytopathic lymphocytic choriomeningitis virus (LCMV) caused hepatocyte damage, as revealed by elevated serum alanin-aminotransferase (ALT) activities and serum bilirubin concentrations ${ }^{5}$ (Fig. 1a). Virus-specific $\mathrm{T}$ cells are a major determinant of the outcome of hepatitis-these cells contribute to the early control of chronic hepatitis viruses and mediate immunopathology during persistent virus infection ${ }^{1-4}$. In a model of LCMV-induced hepatitis, complete depletion of $\mathrm{CD}^{+} \mathrm{T}$ cells enhanced virus replication, but strongly reduced hepatocyte damage (Fig. 1a), showing that the activation of virus-specific $\mathrm{CD}^{+} \mathrm{T}$ cells by viral antigen and not LCMV replication alone is responsible for liver cell damage, confirming earlier results ${ }^{5,6}$. To induce a delayed appearance of $\mathrm{CD}^{+} \mathrm{T}$ cells within the liver, we treated C57BL/6 mice with a 1:10 dilution of a CD8 cell-depleting antibody, which leads to a transient absence of $\mathrm{CD}^{+} \mathrm{T}$ cells. After 8-12 days, $\mathrm{CD} 8^{+} \mathrm{T}$ cells re-emerged (Fig. $\mathbf{1 b}$ ). The delayed $\mathrm{CD}^{+} \mathrm{T}$ cell response within the liver was associated with prolonged viral replication and enhanced ALT levels in the serum when $\mathrm{CD} 8^{+} \mathrm{T}$ cells re-emerged (Fig. $\mathbf{1 b}$ ).

Therefore, similarly to the situation in human hepatitis ${ }^{7-11}$, delayed control of LCMV in the liver enhanced the overall immunopathology in the liver.

Infection and virus-induced hepatitis have been linked to platelet activation ${ }^{12-14}$. To study the role of platelet activation in LCMVtriggered $\mathrm{CD} 8^{+} \mathrm{T}$ cell-dependent hepatitis, we histologically stained liver infiltrates with antibodies specific for the platelet markers CD61 or von Willebrand factor (vWF). Periportal infiltrates of $\mathrm{CD}^{+} \mathrm{T}$ cells contained platelets (Fig. 1c). Serum concentrations of soluble P-selectin increased during infection (Fig. 1d), indicative of extensive platelet-endothelial cell interactions ${ }^{15}$. $\mathrm{CD}^{+} \mathrm{T}$ cells were necessary for virus-induced platelet activation and recruitment, as shown in $C d 8 a^{-/-}$ mice that had attenuated platelet infiltration into the liver together with reduced serum P-selectin concentrations (Fig. 1d,e). Because activated platelets physiologically reduce blood flow, we wanted to determine whether LCMV-induced platelet activation influences hepatic microcirculation ${ }^{16}$. For this purpose, we injected soluble sodium fluorescein into the portal vein of LCMV-infected mice and monitored

\footnotetext{
${ }^{1}$ Institute of Experimental Immunology, University Hospital of Zurich, Schmelzberstrasse 12, CH-8091 Zurich, Switzerland. ${ }^{2}$ Campbell Family Institute for Breast Cancer Research, Ontario Cancer Institute, UHN, 620 University Avenue, Toronto, Ontario M5G 2C1, Canada. ${ }^{3}$ Division of Plastic and Reconstructive Surgery, ${ }^{4}$ Swiss Hepato-Pancreato-Biliary Center, Department of Surgery and ${ }^{5}$ Department of Surgical Pathology, University Hospital of Zurich, Schmelzberstrasse 12 , CH-8091 Zurich, Switzerland. ${ }^{6}$ Research Department, Kantonal Hospital St Gallen, Rorschacher Strasse 95, CH-9007 St Gallen, Switzerland. ${ }^{7}$ Institute of Neuropathology, Georg August University Göttingen, Robert-Koch-Strasse 40, D-37075 Göttingen, Germany. ${ }^{8}$ Max-Delbrück-Center for Molecular Medicine, Robert-Rössle-Strasse 10,13125 Berlin-Buch, Germany. ${ }^{9}$ Department of Rheumatology and Clinical Immunology, Charité-University Medicine Berlin and Deutsches Rheuma-Forschungszentrum Berlin, Schumannstrasse 21-22, 10117 Berlin, Germany. ${ }^{10}$ These authors contributed equally to this work. ${ }^{11}$ These authors contributed equally to this work. Correspondence should be addressed to R.M.Z. (rolf.zinkernagel@usz.ch) or K.S.L. (karlslang@gmail.com).
} 
a
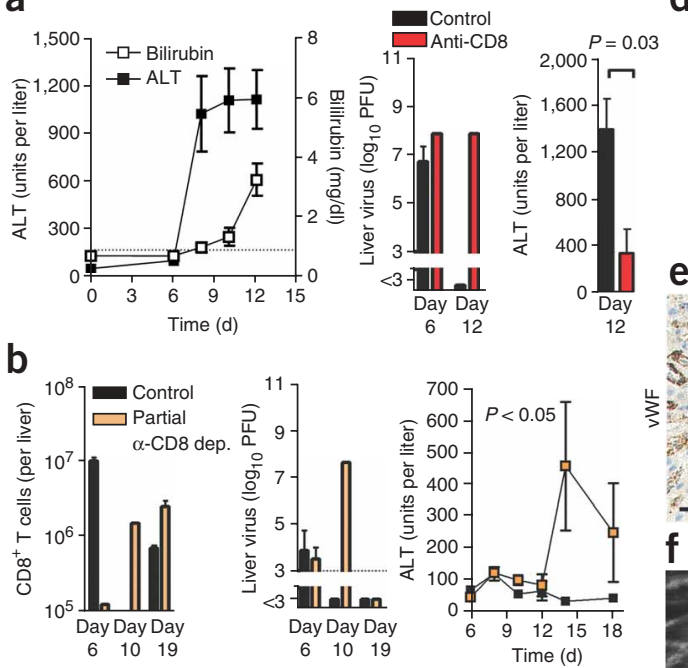

d
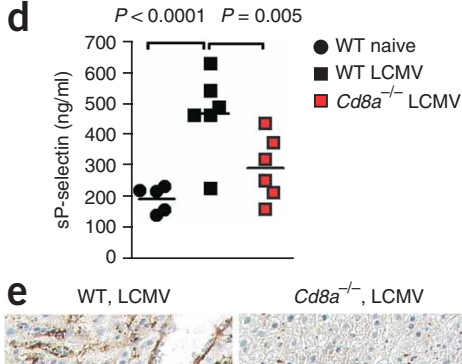
$\mathrm{Cd} 8 \mathrm{a}^{-/-}, \mathrm{LCMV}$

C

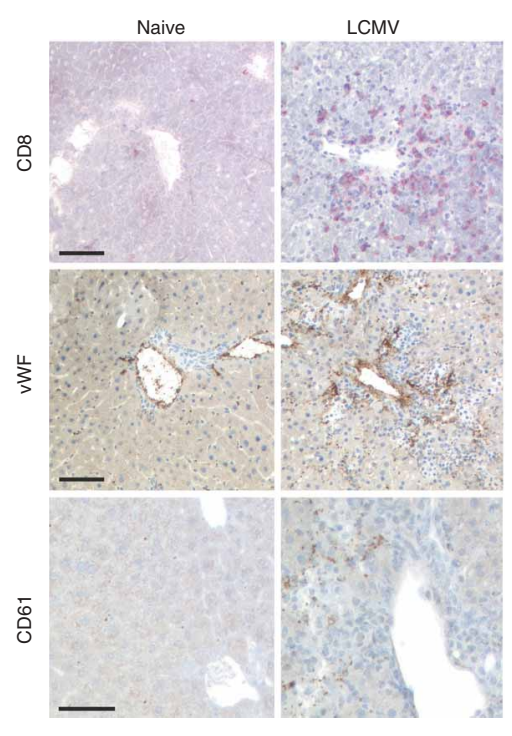

123

\section{(1)}
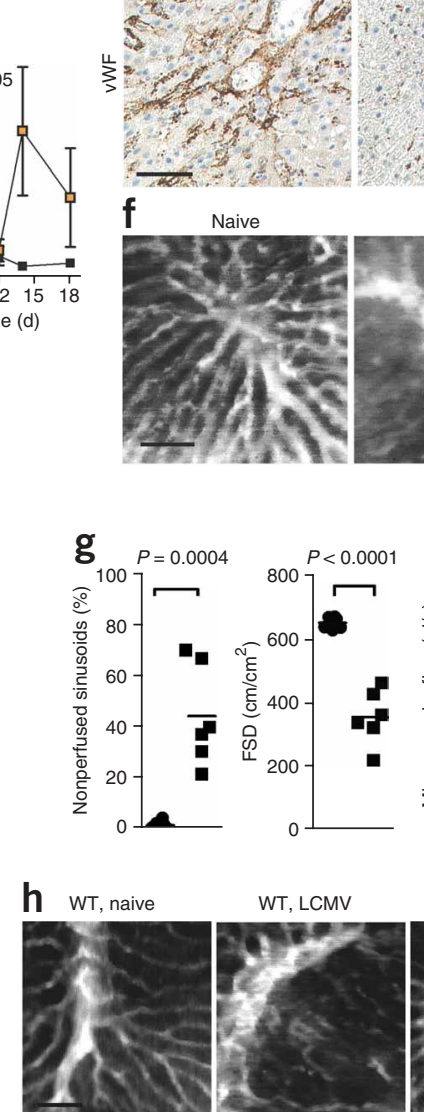

WT, LCMV

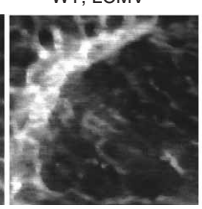

Anti-CD8, LCMV

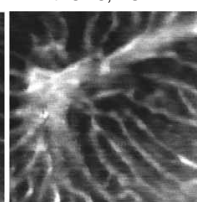

Figure 1 LCMV infection results in platelet activation and reduced blood flow within the liver. (a) Left, C57BL/6 mice were infected with $2 \times$ $10^{6}$ PFU of LCMV-WE and serum was analyzed for ALT and bilirubin ( $n=5$ or 6 ). Middle and right, C57BL/6 mice were completely depleted of $\mathrm{CD}^{+} \mathrm{T}$ cells and infected with $2 \times 10^{5} \mathrm{PFU}$ (middle) or $2 \times 10^{6}$ PFU (right) of LCMV-WE. Viral titers (middle, $n=2$ ) and ALT abundance (right, $n=3$ ) were determined. (b) C57BL/6 mice were partially depleted of $\mathrm{CD} 8^{+} \mathrm{T}$ cells and infected with $2 \times 10^{4}$ PFU of LCMV-WE. CD8 ${ }^{+}$ $T$ cell counts (left), viral replication (middle, $n=2$ or 3 ) and ALT abundance (right, $n=5-8$ ) were determined. (c) C57BL/6 mice were infected with $2 \times 10^{6}$ PFU of LCMV-WE. On day 8 , the presence of $\mathrm{CD} 8^{+} \mathrm{T}$ cells and platelets ( $\mathrm{VWF}^{+}$ or $\mathrm{CD} 1^{+}, n=3$ ) within livers was analyzed. (d,e) $\mathrm{Cd} \mathrm{a}^{-/-}$and WT mice were infected with $2 \times 10^{6}$ PFU of LCMV-WE. Seven days later, plasma soluble P-selectin (d, $n=5$ or 6 ) and expression of vWF in the liver $(\mathbf{e}, n=3)$ were analyzed. (f,g) On days 5 or 6 after LCMV infection, liver microcirculation was analyzed. (f) A representative picture of sinusoidal flow. (g) Quantifications of parameters of microcirculation $(n=6)$. (h) C57BL/6 mice were completely depleted of CD8 $8^{+} \mathrm{T}$ cells and infected with $2 \times 10^{6}$ PFU of LCMV-WE. On days 5 or 6 , liver microcirculation was analyzed. A representative picture of sinusoidal flow is shown. Scale bars, $60 \mu \mathrm{m}$. Data are expressed as means \pm s.e.m.

infected mice lacking tryptophan hydroxylase-1 $\left(T p h 1^{--}\right)$, which is required for the synthesis of peripheral serotonin ${ }^{23}$, with LCMV. In contrast to wild-type (WT) mice, intravital microscopy of $T p h 1^{-1-}$ mice showed normal red blood cell (RBC) velocity and perfusion within liver sinusoids after LCMV infection (Fig. 2a,b) despite similar platelet activation (Supplementary Fig. 1). Notably, naive $T p h 1^{-1-}$ mice also showed a somewhat dye diffusion by intravital fluorescence microscopy. LCMV infection resulted in a striking perfusion failure in nearly $50 \%$ of sinusoids (Fig. 1f,g), an effect that was dependent on activation of $\mathrm{CD}^{+} \mathrm{T}$ cells (Fig. 1h). Consistent with these findings, the total length of all perfused sinusoids per visual field (functional sinusoid density, FSD) was strongly reduced in LCMV-infected animals (Fig. 1g). The remaining functional sinusoids showed reduced microvascular flow (Fig. 1g). Taken together, these data indicate a strong correlation between $\mathrm{CD}^{+} \mathrm{T}$ cell-dependent platelet recruitment and reduction of hepatic microcirculation.

Platelet activation results in the release of vasoactive serotonin ${ }^{17-20}$, which can reduce sinusoidal microcirculation in the liver ${ }^{21,22}$. To determine whether LCMV infection caused local release of plateletderived serotonin within the liver, we infected C57BL/6 mice with $2 \times$ $10^{6}$ plaque-forming units (PFU) of LCMV strain WE (LCMV-WE) and then analyzed blood platelet number and serum serotonin abundance. Circulating platelet numbers and half-life were reduced by LCMV infection, which correlated with lowered serum serotonin and enhanced release of serotonin within the liver (Supplementary Fig. 1 online). To assess the role of serotonin in sinusoidal flow, we enhanced sinusoidal perfusion, suggesting that serotonin has a role in regulating liver microcirculation in the absence of infection. Decreased microcirculation during LCMV infection correlated with reduced tissue oxygen tension and enhanced levels of lactate, glycerol, serum ALT and serum bilirubin in the livers of WT mice, indicating extensive hepatocyte damage (Fig. 2c-d). For each of the markers examined, LCMV infection resulted in less extensive immunopathological hepatocyte injury in Tph $1^{-/-}$mice (Fig. 2c-d). Consistent with the reduced damage, livers of $T p h 1^{-1-}$ mice showed less fibrosis after LCMV infection, as measured by staining of $\alpha$-smooth muscle actin $(\alpha$-SMA $)$ and induction of collagen within the liver on day 12 (Fig. 2e,f). The influence of serotonin on hepatitis was further demonstrated by treating WT mice with the serotonin reuptake inhibitor fluoxetine. Fluoxetine inhibits the serotonin uptake of platelets from enterochromaffin cells within the gut ${ }^{24}$, and, indeed, it depleted serotonin storages in platelets and reduced liver cell damage in our experiments (Supplementary Fig. 2 online). Consistent with the serotonin-dependent liver pathology in adult mice, we found a serotonin-dependent induction of steatosis after LCMV infection of newborn mice (Supplementary Fig. 3 online). Thus, 

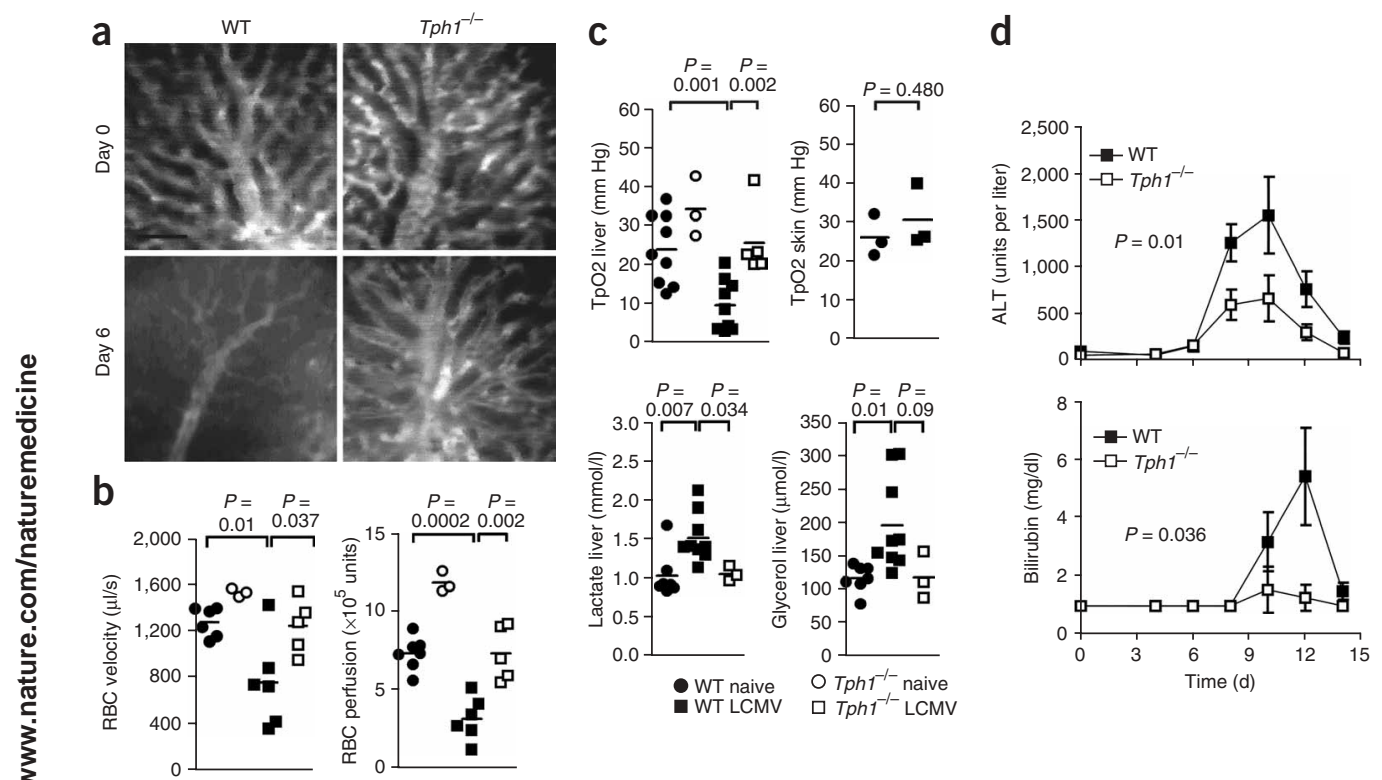

e

Figure 2 Platelet-derived serotonin mediates LCMV-induced reductions in liver blood flow. Tph1 $1^{-1-}$ or WT mice were infected with $2 \times 10^{6}$ PFU LCMV. (a,b) Liver blood flow was analyzed by intravital microscopy on days 5 and 6 after infection. (a) Image showing liver sinusoids during analysis of sinusoidal flow. (b) Evaluation of RBC velocity and RBC perfusion within liver sinusoids in infected and noninfected (naive) mice $(n=3-7)$. (c) Tissue oxygen tension $\left(\mathrm{TpO}_{2}\right)$ in liver (top left) and skin (top right, as control) and lactate (bottom left) and glycerol (bottom right) concentrations in liver were determined by microdialysis $(n=3-9$ ). (d) Serum ALT (top, $n=9$ ) and bilirubin concentrations (bottom, $n=4$ ) were analyzed at the indicated time points after LCMV infection. (e) Livers from the indicated mice were analyzed for the fibrosis marker $\alpha$-SMA $(n=3)$ on day 12 by immunohistochemistry. (f) Expression of collagen mRNA was determined in livers of C57BL/6 and Tph ${ }^{-1-}$ mice on day 12 after infection by quantitative RT-PCR $(n=3)$. Scale bars, $60 \mu \mathrm{m}$. Data are expressed as means \pm s.e.m.

serotonin resulted in reduced microcirculation and enhanced immunopathological liver cell damage but also promoted aspects of chronic hepatitis such as fibrosis and steatosis.

To examine whether serotonin influenced $\mathrm{T}$ cell responses, we examined $\mathrm{T}$ cell activation and virus replication in WT and $T p h 1^{-1-}$ mice. We found no difference in viral replication until day 6 (Fig. 3a). After day 6, however, $T p h 1^{-1-}$ mice controlled viral antigen, whereas it still persisted in WT mice (Fig. 3a). These findings were confirmed by immunohistology, which showed virus antigen within hepatocytes on day 8 in WT mice, whereas virus was hardly detectable at this time point in $T$ ph $1^{-1-}$ mice ${ }^{25}$ (Fig. 3b). We did not find differences in the innate immune response between WT and Tph $1^{-1-}$ mice, as tested by serum interferon- $\alpha$ (IFN- $\alpha)$, infiltration of granulocytes and activation of Kupffer cells (Supplementary Fig. 4 online). In line with these findings, we did not observe differences between WT and $T p h 1^{-1-}$ mice in the distribution and replication of mouse hepatitis virus, which is efficiently controlled by the innate immune system (Supplementary Fig. 5 online $)^{26}$. Depletion of $\mathrm{CD}^{+} \mathrm{T}$ cells in WT and $\mathrm{Tph} 1^{-1-}$ mice showed that the differential virus elimination in $T p h 1^{-l-}$ mice was dependent on functional $\mathrm{CD}^{+} \mathrm{T}$ cells (Fig. 3a,c). $\mathrm{CD}^{+} \mathrm{T}$ cell phenotype (Fig. 3d) and function, as determined by IFN- $\gamma$ production and cytotoxic activity, were normal in the $T p h 1^{-1-}$ mice (Fig. 3e). No obvious differences were observed for IFN- $\gamma$ production by virusspecific $\mathrm{CD}^{+} \mathrm{T}$ cells between $T p h 1^{-/-}$and WT mice (Supplementary Fig. 6 online). Frequencies of virus-specific $\mathrm{CD} 8^{+} \mathrm{T}$ cells expressing specificity for the LCMV GP33-41 epitope were determined by binding of major histocompatibility complex class I-gp33 tetramers (tet-gp33) and were comparable between $T p h 1^{-/-}$and WT mice (Fig. 3f). The total numbers of $\mathrm{CD}^{+} \mathrm{T}$ cells in the liver and spleen were similar in WT and $T p h 1^{-1-}$ mice on days 4,6 and 8 (Fig. 3f).
Because a microcirculatory dysfunction might influence the distribution of $\mathrm{CD}^{+} \mathrm{T}$ cells within the liver, we determined the numbers of periportal versus intralobular $\mathrm{CD}^{+} \mathrm{T}$ cells by histology. Using a previously described method ${ }^{27}$, we found that a significantly higher proportion of $\mathrm{CD}^{+} \mathrm{T}$ cells were located intralobularly in $\mathrm{Tph} 1^{-/-}$mice $(P=0.03$, Fig. 3f $)$. These findings have been correlated with enhanced control of viral replication and subsequent reduction of immunopathology in humans ${ }^{27}$. These findings could therefore explain the enhanced viral control and reduction of pathology in Tph1 $1^{-1-}$ mice.

To further document the importance of serotonin for virus-induced hepatitis, we treated WT mice with exogenous serotonin. Because we expected this treatment to enhance virally-induced liver immunopathology, we lowered the dose of LCMV to a level that is below the threshold for induction of hepatitis. Control mice, not receiving additional serotonin, showed only a mild increase in serum ALT, whereas serotonin-treated mice showed strongly increased serum ALT (Fig. 4a). Early priming of antiviral $\mathrm{CD}^{+} \mathrm{T}$ cell responses was not influenced by serotonin, but these cells did show some phenotypic differences during later stages of the infection (Fig. 4 b and Supplementary Fig. 7 online). Six days after infection, the entry of activated tet-gp $33^{+} \mathrm{CD}^{+} \mathrm{T}$ cells into the liver was delayed in mice treated with serotonin (Fig. 4c), which is consistent with the differences found in $\mathrm{CD}^{+} \mathrm{T}$ cell distribution in $\mathrm{Tph} 1^{-1-}$ mice (Fig. 3f). These results suggest that the antiviral $\mathrm{CD}^{+} \mathrm{T}$ cell response was delayed by the serotonin treatment. This was confirmed in two additional models in which a viral antigen is constantly expressed in the liver (Supplementary Fig. 8 online). In line with the reduced $\mathrm{CD}^{+} \mathrm{T}$ cell response, replication of LCMV was enhanced in serotonin-treated mice (Fig. 4d). From these data, we concluded that serotonin delays the 
a

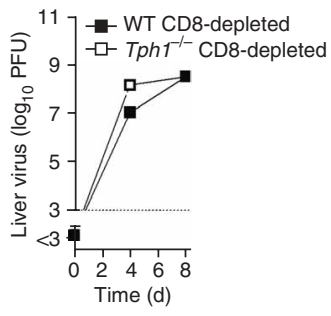

b $\quad$ WT

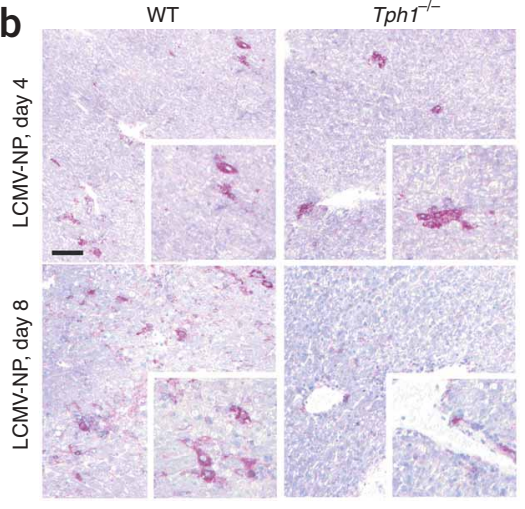

C

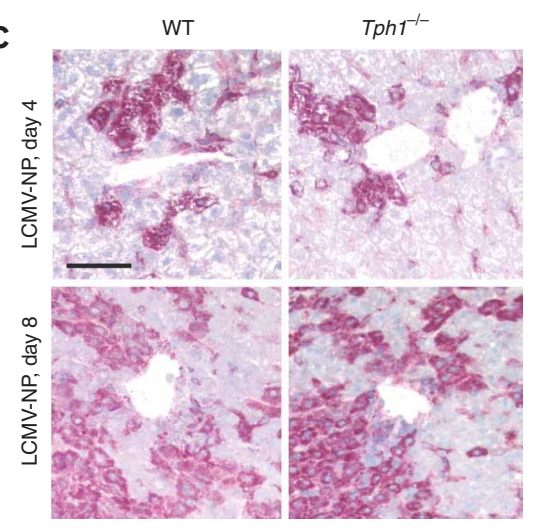

e
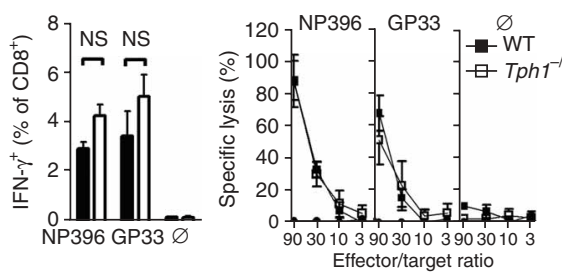
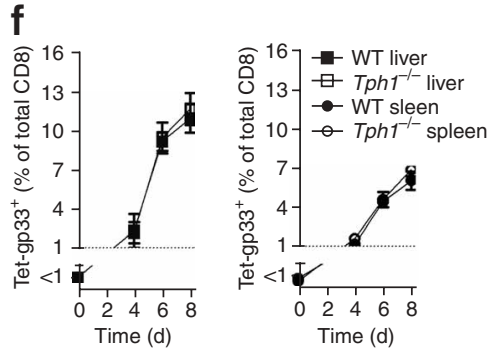

Figure 3 Serotonin has no impact on $\mathrm{CD}^{+} \mathrm{T}$ cell priming. Tph $1^{-/-}$mice and the corresponding control mice were infected with $2 \times 10^{6}$ PFU of LCMV-WE. (a) Virus titers were analyzed by plaque assay with (left) or without (right) prior in vivo depletion of $\mathrm{CD}^{+}$T cells $(n=4-7 ; n=2$ for anti-CD8-treated mice). (b) Virus distribution on days 4 and 8 after infection was analyzed by immunohistochemistry of

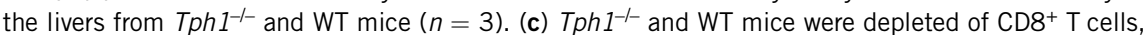
and virus distribution was analyzed on days 4 and $8(n=2)$. (d) CD8 $8^{+}$T cells in the liver were analyzed for expression of the interleukin-7 receptor alpha chain (CD127), the lymph node homing receptor CD62L, the receptor for vascular cell adhesion molecule-1 (CD49d) and the CTL effector molecule granzyme B. One out of six representative histogram plots is shown. The percentages of cells expressing an activated phenotype are shown. For naive $\mathrm{CD} 8^{+} \mathrm{T}$ cells (gray area) the percentages of cells that fell into the indicated region for activation were 33\% (CD127), 10\% (CD62L), 6\% (CD49d) and 1\%

\section{(Granzyme B). (e) Effector function of virus-specific $\mathrm{CD} 8^{+} \mathrm{T}$ cells isolated from the spleen at day 8 after}
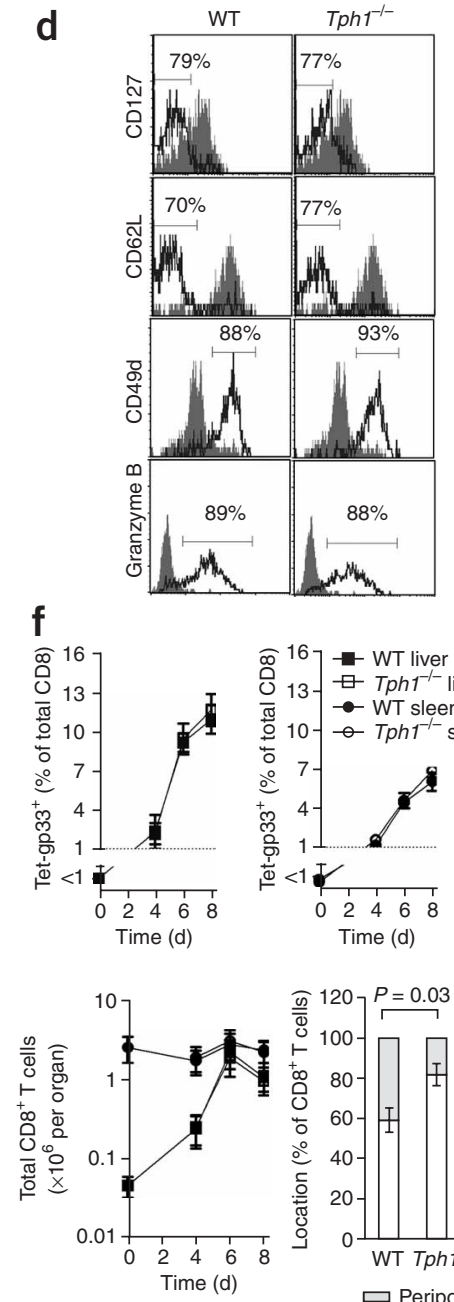

infection is shown as determined by intracellular IFN- $\gamma$ staining of cells subjected to in vitro restimulation with LCMV peptide (left) and direct ex vivo cytotoxicity assays (right; $n=3$, one of two similar experiments is shown). (f) Total CD8 ${ }^{+}$T cell numbers (bottom left) and the frequency of tet-gp33 ${ }^{+} \mathrm{CD} 8^{+}$ T cells (top) were analyzed by flow cytometry and are shown for the spleen and liver $(n=6-7)$. The location of CD8 $8^{+}$cells was analyzed on histological sections of the liver (bottom right; $n=5$ ). The number of periportal versus intralobular CD8 ${ }^{+}$T cells is given as percentage of total liver-infiltrating $\mathrm{CD} 8^{+}$ T cells. Scale bars, $60 \mu \mathrm{m}$. Data are expressed as means \pm s.e.m.

antiviral $\mathrm{CD}^{+} \mathrm{T}$ cell response within the liver, which results in enhanced viral replication.

In view of the delay in the early $\mathrm{CD} 8^{+} \mathrm{T}$ cell response, we postulated that the increased and persistent antigen load in the liver should prolong local $\mathrm{CD}^{+} \mathrm{T}$ cell cytotoxicity. To address this possibility, we treated mice with serotonin with or without depletion of $\mathrm{CD} 8^{+} \mathrm{T}$ cells. Indeed, we found a complete reduction of hepatitis when $\mathrm{CD}^{+} \mathrm{T}$ cells were depleted in serotonin-treated mice (Fig. 4e), suggesting that the prolonged activation of $\mathrm{CD}^{+} \mathrm{T}$ cells by not-yet-controlled antigen is the mechanism of serotonin-induced liver cell damage.

In conclusion, this study has demonstrated that during infection with a noncytopathic virus, serotonin release is responsible for sinusoidal microcirculatory failure. Serotonin-dependent alterations in sinusoidal microcirculation account for viral-induced liver cell damage by delaying the infiltration of activated virus-specific $\mathrm{CD}^{+}$ $\mathrm{T}$ cells and thereby protracting viral control. In human hepatitis, a delay in $\mathrm{CD}^{+} \mathrm{T}$ cell responses will favor virus replication to levels that lead to persistence of virus. Our study suggests that serotonin aggravates viral control and therefore favors onset of chronic hepatitis.

\section{METHODS}

Mice, viruses and serotonin treatment. We propagated LCMV strain WE in L929 cells. We measured virus titers with a focus-forming assay as previously described $^{28}$. We treated mice with $150 \mathrm{mg}$ serotonin per kg body weight per day (dissolved in $200 \mu \mathrm{l}$ water) by intraperitoneal injection. Control mice received $200 \mu \mathrm{l}$ water. All mice were on a C57BL/6 background, were kept in single ventilated cages and were experimentally treated by authorization of the Veterinäramt of the Kanton Zurich and according to Swiss laws for animal protection.

Depletion of $\mathrm{CDB}^{+} \mathrm{T}$ cells and cytotoxicity assay. We depleted $\mathrm{CD} 8^{+} \mathrm{T}$ cells by intraperitoneal or intravenous injection of rat monoclonal antibody specific for mouse CD8 (clone YTS169.4) $2 \mathrm{~d}$ and $1 \mathrm{~d}$ before infection. For partial depletion, we diluted antibody 1:10. We analyzed cytotoxicity against the epitopes GP33 and NP396 in a ${ }^{51} \mathrm{Cr}$ release assay as previously described ${ }^{28}$. We analyzed supernatants after $8 \mathrm{~h}$ of culture.

Histology. Histological analyses were performed as previously described ${ }^{28}$ with monoclonal antibodies to mouse CD8 (made in house), LCMV-NP (clone VL4 (made in house)), CD61 (BD Biosciences) and $\alpha$-SMA (Dako) and polyclonal rabbit antibodies to vWF (Dako). For quantitative analysis of $\mathrm{CD}^{+} \mathrm{T}$ cells in the liver, we used the method described recently ${ }^{27}$. 


\section{LET TER S}

a

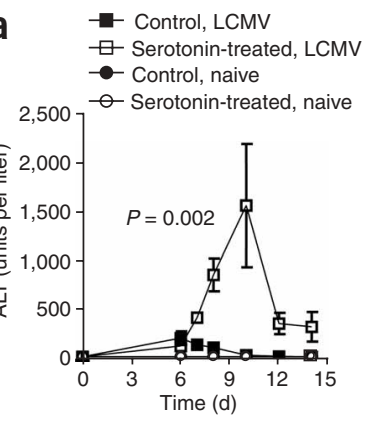

Figure 4 Exogenous serotonin aggravates viral hepatitis. C57BL/6 mice were infected with $2 \times 10^{4} \mathrm{PFU}$ of LCMV-WE and were additionally treated with serotonin (150 mg per kg body weight per day) or with water as a control. (a) ALT activity in the serum of infected mice was analyzed at the indicated time points $(n=6-12)$. (b) LCMV-specific T cells (tet-gp33+ and tet-np396+, left) were analyzed in the blood on day 8 after infection $(n=6)$. Cytotoxic T cell activity (middle) was analyzed in the spleen at day 6 after infection $(n=3)$. Numbers of IL-7R $\alpha^{+}$LCMV-specific (tet-gp33 $3^{+}$) $\mathrm{CD} 8^{+} \mathrm{T}$ cells (right) and expansion capacity of $\mathrm{CD} 8^{+} \mathrm{T}$ cells were also analyzed (Supplementary Fig. 7). (c) P14 T cell receptor-transgenic mice (specific for the LCMV gp33 epitope) were infected with LCMV, and activated splenocytes were harvested $6 \mathrm{~d}$ later. Splenocytes $\left(3 \times 10^{6}\right.$ cells $)$ were injected into WT recipients infected $6 \mathrm{~d}$ previously with LCMV and additionally treated with serotonin or water as a control. Mice were killed at 1, 30 or 120 min after transfer, and the number of transferred P14 CD8 $8^{+}$T cells in the liver was determined by flow cytometry (left, $n=2$ or 3 per time point). The total number of CD8 ${ }^{+}$T cells in the liver (right, endogenous $\mathrm{CD}^{+} \mathrm{T}$ cell response) was determined in all mice $(n=11$ or 12). (d) At day 8 after infection, spleens (left), livers (middle) and kidneys (right) were removed and analyzed for virus titers $\left(n=5\right.$ or 6 ). (e) Before infection, one group of mice was depleted of CD8 ${ }^{+}$T cells. ALT was analyzed at day $9(n=3)$. Data are expressed as means \pm s.e.m.

Bilirubin, alkaline phosphatase and alanine aminotransferase. We measured bilirubin, alkaline phosphatase and ALT abundance with a serum multiple biochemical analyzer (Ektachem DTSCII, Johnson \& Johnson).

ELISAs. We performed IFN- $\alpha$ ELISAs (Research Diagnostics), P-selectin ELISAs on plasma according to the manufacturer's instructions (Quantikine, R\&D Systems) and serotonin ELISAs on plasma (GenWay) according to the manufacturer's instructions. For serotonin ELISAs, we calculated standard 20 curves using a half-logarithmic scale. We removed livers and immediately froze them in liquid nitrogen, then weighed and homogenized them in perchloric acid. Values were normalized for the liver weight and presented as $\mathrm{ng} / \mathrm{ml}$ of tissue homogenate.

FACS analysis. To stain for LCMV-specific $\mathrm{CD} 8^{+} \mathrm{T}$ cells, we used tetramers as previously described ${ }^{28}$. We purchased monoclonal antibodies to mouse CD8, IFN- $\gamma$, CD127, CD62L, CD61 and CD49d from BD Biosciences. We purchased monoclonal antibody to granzyme $\mathrm{B}$ from Caltag.

Hepatic microcirculation. We studied hepatic microcirculation by intravital fluorescence microscopy (Leica DM/LM; Leica Microsystems) with a blue filter (excitation $450-490 \mathrm{~nm} />520 \mathrm{~nm}$, excitation/emission wavelength). We visualized sinusoidal perfusion under blue-filtered light after injection of soluble sodium fluorescein $(2 \mu \mathrm{mol} / \mathrm{kg} \text { intra-arterially, Fluka Chemie })^{16}$. We recorded ten randomly chosen nonoverlapping Rappaport acini for $30 \mathrm{~s}$ each. We assessed hepatic microcirculatory parameters off-line by means of frame-toframe analysis of the videotaped images using a computer-assisted image analysis system (CapImage; Zeintl). We determined sinusoidal perfusion ratios by calculating the ratio of perfused sinusoids against the total number of visible sinusoids and represent them as the percentage of nonperfused sinusoids. We defined FSD as the total length of all perfused sinusoids per observation area $\left(\mathrm{cm} / \mathrm{cm}^{2}\right)^{29}$. We measured sinusoidal diameters $(\mu \mathrm{m})$ perpendicularly to the vessel pad. We calculated sinusoidal RBC flow from diameter and RBC velocity. We calculated hepatic RBC perfusion index by the product of FSD and RBC velocity.
mRNA gene profiling by quantitative reverse transcription-PCR. We performed RNA extraction and production of cDNA as previously described ${ }^{28}$. We performed gene expression analysis of collagen and 18S ribosomal RNA with kits from Applied Biosystems. For analysis, we normalized the expression levels of all target genes against $18 \mathrm{~S}$ rRNA $\left(\Delta C_{T}\right)$. Gene expression values were then calculated on the basis of the $\Delta \Delta C_{T}$ method, using the mean value from three untreated mice as a calibrator to which all other samples were compared. We determined relative quantities (RQ) using the following equation: $\mathrm{RQ}=2^{-\Delta \Delta C} T$.

Microdialysis. We measured parenchymal liver concentrations of glucose, lactate and glycerol using microdialysis probes (CMA/20, CMA Microdialysis $\mathrm{AB}$ ) with a molecular weight cut-off of 20,000 Da and membrane length of $5 \mathrm{~mm}$ as previously described ${ }^{16}$.

Tissue oxygen tension. We assessed partial tissue oxygen tension with Clarktype microprobes consisting of polarographic electrodes and an oxygensensitive microcell (Revoxode CC1).

Statistical analyses. Data are expressed as mean \pm s.e.m. and were analyzed with Student's $t$-test. Analyses including repeated measurements or comparison of more than two groups were tested either with repeated two-way ANOVA or one-way ANOVA followed by Bonferoni or Dunnett tests.

Note: Supplementary information is available on the Nature Medicine website.

\section{ACKNOWLEDGMENTS} I. Markewitz, A. Helminski and S. Behnke for histological analysis. This study was supported by the Swiss National Science Foundation grants 3100A0100779 (to H.H.) and 3100A0-100068 (to R.M.Z.) and the Canadian Institutes of Health Research grant to P.S.O. K.S.L. was partially supported by the Jung-Stiftung für Wissenschaft und Forschung. P.A.L. was supported by SFB/Transregio6040. A.N.H. is a fellow of GRAKO1121 of the German Research Foundation. M.L. is a Lichtenberg fellow funded by the Volkswagen Foundation.
We would like to thank I. Miescher for technical support and A. Fitsche, 


\section{AUTHOR CONTRIBUTIONS}

P.A.L., C.C. and P.G. planned and performed most experiments. A.M.E.-B. performed hepatic microcirculation experiments. D.M., B.O. and M.K. performed and analyzed histology. L.C.-B., B.L. and B.B. performed adenovirus and mouse hepatitis virus experiments. T.C. and A.N.H. performed some experiments. M.B., R.G., P.-A.C., M.L. and N.L.H. discussed and interpreted results. M.R., P.S.O. and H.H. came up with ideas and helped write the manuscript. R.M.Z. and K.S.L. designed the study and wrote the manuscript.

Published online at http://www.nature.com/naturemedicine/

Reprints and permissions information is available online at http://npg.nature.com/
1. Rehermann, B. \& Nascimbeni, M. Immunology of hepatitis $B$ virus and hepatitis $C$ virus infection. Nat. Rev. Immunol. 5, 215-229 (2005).

2. Urbani, S. et al. Heterologous T cell immunity in severe hepatitis $\mathrm{C}$ virus infection. J. Exp. Med. 201, 675-680 (2005).

3. Thimme, R. et al. Determinants of viral clearance and persistence during acute hepatitis C virus infection. J. Exp. Med. 194, 1395-1406 (2001).

4. Sobao, Y. et al. The role of hepatitis B virus-specific memory CD8 T cells in the control of viral replication. J. Hepatol. 36, 105-115 (2002).

5. Zinkernagel, R.M. et al. T cell-mediated hepatitis in mice infected with lymphocytic choriomeningitis virus. Liver cell destruction by $\mathrm{H}-2$ class I-restricted virus-specific cytotoxic T cells as a physiological correlate of the 51Cr-release assay? J. Exp. Med. 164, 1075-1092 (1986).

6. Recher, M. et al. Extralymphatic virus sancturies as a consequence of potent T cell activation. Nat. Med. 13, 1316-1323 (2007).

7. Thimme, R. et al. $\mathrm{CD}^{+}$Tcells mediate viral clearance and disease pathogenesis during acute hepatitis B virus infection. J. Virol. 77, 68-76 (2003).

8. Nakamura, I. et al. Pathogenesis of experimental neonatal woodchuck hepatitis virus infection: chronicity as an outcome of infection is associated with a diminished acute hepatitis that is temporally deficient for the expression of interferon $\gamma$ and tumor necrosis factor- $\alpha$ messenger RNAs. Hepatology 33, 439-447 (2001).

9. Murray, J.M., Wieland, S.F., Purcell, R.H. \& Chisari, F.V. Dynamics of hepatitis B virus clearance in chimpanzees. Proc. Natl. Acad. Sci. USA 102, 17780-17785 (2005).

10. Gregory, P.B., Knauer, C.M., Kempson, R.L. \& Miller, R. Steroid therapy in severe viral hepatitis. A double-blind, randomized trial of methyl-prednisolone versus placebo. N. Engl. J. Med. 294, 681-687 (1976).

11. Bertoletti, A. \& Gehring, A.J. The immune response during hepatitis B virus infection. J. Gen. Virol. 87, 1439-1449 (2006).
12. Panasiuk, A. et al. Activation of blood platelets in chronic hepatitis and liver cirrhosis P-selectin expression on blood platelets and secretory activity of beta-thromboglobulin and platelet factor-4. Hepatogastroenterology 48, 818-822 (2001).

13. Iannacone, M. et al. Platelets prevent IFN- $\alpha / \beta$-induced lethal hemorrhage promoting CTL-dependent clearance of lymphocytic choriomeningitis virus. Proc. Natl. Acad. Sci. USA 105, 629-634 (2008).

14. Iannacone, M. et al. Platelets mediate cytotoxic T lymphocyte-induced liver damage. Nat. Med. 11, 1167-1169 (2005).

15. Blann, A.D. \& Lip, G.Y. Hypothesis: is soluble P-selectin a new marker of platelet activation? Atherosclerosis 128, 135-138 (1997).

16. Contaldo, C. et al. The influence of trauma and ischemia on carbohydrate metabolites monitored in hamster flap tissue. Anesth. Analg. 100, 817-822 (2005).

17. Van Nueten, J.M. Serotonin and the blood vessel wall. J. Cardiovasc. Pharmacol. 7 Suppl 7, S49-S51 (1985).

18. Van Nueten, J.M., Janssens, W.J. \& Vanhoutte, P.M. Serotonin and vascular reactivity. Pharmacol. Res. Commun. 17, 585-608 (1985).

19. Walther, D.J. et al. Serotonylation of small GTPases is a signal transduction pathway that triggers platelet alpha-granule release. Cell 115, 851-862 (2003).

20. Lesurtel, M. et al. Platelet-derived serotonin mediates liver regeneration. Science $\mathbf{3 1 2}$, 104-107 (2006).

21. Blankenship, L.L. Jr., Cilento, E.V. \& Reilly, F.D. Hepatic microvascular regulatory mechanisms. XI. Effects of serotonin on intralobular perfusion and volumetric flowrates at the inlet of periportal and outlet of centrivenous sinusoids. Microcirc. Endothelium Lymphatics 7, 57-75 (1991).

22. Cummings, J.L., Cilento, E.V. \& Reilly, F.D. Hepatic microvascular regulatory mechanisms. XII. Effects of 5-HT2-receptor blockade on serotonin-induced intralobular hypoperfusion. Int. J. Microcirc. Clin. Exp. 13, 99-112 (1993).

23. Walther, D.J. et al. Synthesis of serotonin by a second tryptophan hydroxylase isoform. Science 299, 76 (2003)

24. Born, G.V., Juengjaroen, K. \& Michal, F. Relative activities on and uptake by human blood platelets of 5-hydroxytryptamine and several analogues. Br. J. Pharmacol. $\mathbf{4 4}$, 117-139 (1972).

25. Bergthaler, A., Merkler, D., Horvath, E., Bestmann, L. \& Pinschewer, D.D. Contributions of the lymphocytic choriomeningitis virus glycoprotein and polymerase to strainspecific differences in murine liver pathogenicity. J. Gen. Virol. 88, 592-603 (2007).

26. Cervantes-Barragan, L. et al. Control of coronavirus infection through plasmacytoid dendritic cell-derived type I interferon. Blood 109, 1131-1137 (2007).

27. Maini, M.K. et al. The role of virus-specific CD8(+) cells in liver damage and viral control during persistent hepatitis B virus infection. J. Exp. Med. 191, 1269-1280 (2000).

28. Lang, K.S. et al. Immunoprivileged status of the liver is controlled by Toll-like receptor 3 signaling. J. Clin. Invest. 116, 2456-2463 (2006).

29. Uhlmann, S., UhImann, D. \& Spiegel, H.U. Evaluation of hepatic microcirculation by in vivo microscopy. J. Invest. Surg. 12, 179-193 (1999). 